\title{
Lateral periodontal kist görünümlü radiküler kistin ve eksternal kök rezorpsiyonunun cerrahi ve endodontik tedavisi
}

\section{Surgical endodontic theraphy of a radicular cyst mimicking lateral periodontal cyst and external root resorption}

Hasan Guney Yilmaz, DDS, PhD, Hakan Bayindir, DDS, PhD

Yakın Doğu Üniversitesi, Dişhekimliği Fakültesi, Periodontoloji Anabilim Dalı, Lefkoşa, KKTC.

Received: 16 March 2011 Accepted: 06 June 2011

\section{ÖZET}

Radiküler kistler, enfekte ve nekrotik pulpalı dişlerin apekslerinde oluşan enflamatuar çene kistleridir. Radiküler kistlerin tedavisinde öncelikle ilgili dişe kanal tedavisi uygulanmakta, eğer gerekli görülürse apiksektomi ve retrograd dolgu ile birlikte kistin cerrahi eksizyonu yapılmaktadır. Lateral periodontal kist (LPK) ise çok yaygın olarak görülmeyen, gelişimsel bir odontojenik kisttir. Kökün lateral yüzeyinde, sklerotik kenarlı, iyi sınırlanmış yuvarlak veya oval radyolusent bir görüntü veren LPK genellikle rutin radyografik muayenedetespit edilmektedir. LPK' in ayırıc1 tanısında ilgili dişin vital olması önem kazanmaktadır. Radyolojik inceleme klinik teşhislerde önemli bir kaynaktır ancak yetersiz radyolojik incelemeye bağlı olarak yanlış teşhis, dişin çekimine, gerekli olmayan periodontal tedaviye ve lezyonun rekürrensine neden olabilmektedir. Bu olgu raporunda daha önceden yapılmış başarısız kök kanal tedavisi nedeni ile oluşmuş; lateral periodontal kist görünümlü geniş periradiküler lezyonun ve eksternal kök rezorbsiyonun Erbiyum, Krom: YittriyumScandiyum-Galyum-Garnet (Er,Cr:YSGG) lazer ve mineral trioksit agregat (MTA) kullanılarak yapılan cerrahi endodontik tedavisi sunulmaktadır.

Anahtar kelimeler: Lateral periodonatal kist, radiküler kist, eksternal kök rezorbsiyonu, Er,Cr:YSGG laser, MTA.

\begin{abstract}
Radicular cysts are inflammatory jaw cysts at the apices of teeth with infected and necrotic pulps. Radicular cyst treatment is mainly based on root canal treatment and if necessary surgical excision of the cyst lining with apicoectomy with retrograde filling. The lateral periodontal cyst (LPC) is an uncommon developmental odontogenic cyst. The LPC appears as a well circumscribed round or ovoid radiolucent area, usually with a sclerotic margin on the lateral aspect of a root. The vitality of adjacent teeth plays an important role in the differential diagnosis. Although radiographic examination is an important resource in clinical diagnosis; misdiagnosis may lead to extraction of teeth, unnecessary periodontal treatment and recurrence of the lesion because of inadequate radiologic examination. In this present case, surgical endodontic theraphy of a radicular cyst mimicking lateral periodontal cyst with external root resorption related to previous unsuccessful root canal treatment and large diameters of the lesion by a Erbium, Cronium: Yittrium: Scandium, Gallium and Garnet Er,Cr:YSGG laser and mineral trioxiside aggregate (MTA) is presented.

Key words: Lateral peridontal cyst, radicular cyst, external rooth resorption, Er,Cr:YSGG laser, MTA.
\end{abstract}

Hasan Guney YILMAZ

Yakın Doğu Üniversitesi,

Dişhekimliği Fakültesi,

Periodontoloji Anabilim Dalı,

Lefkoşa, KKTC

Tel: 03926802030/2654

Faks: 03926802025

e-posta: guneyyilmaz@hotmail.com

\section{GİRIŞ}

Lateral periodontal kist (LPK) çok yaygın olarak görülmeyen, gelişimsel bir odontojenik kisttir. Çoğu LPK arkın her iki tarafinda kanin/premolar bölgesinde lokalize olurken \%80' inden fazlası mandibulada yer almaktadır. ${ }^{1}$ Genellikle rutin radyografik muayene sirasinda tespit 
edilen LPK, kökün lateral yüzeyinde, sklerotik kenarlı, iyi sınırlanmış yuvarlak veya oval radyolusent bir görüntü vermektedir. LPK' in patogenezinde mine epiteli, dental lamina artıkları veya Malassez epitel hücre artıkları olmak üzere üç olasılıktan bahsedilmektedir. ${ }^{1-3}$ LPK' in, enflamatuar odontojenik kistlerden ve devital dişlerin lateral kanalları ile bağlantılı kökün lateral yüzeyinde oluşan kistlerden ayırıcı tanısında ilgili dişin vital olması önem kazanmaktadır. ${ }^{1-4}$ LPK' in tedavisinde, kistin tümünün cerrahi eksizyonu önerilmektedir. ${ }^{1}$

Radiküler kistler, enfekte ve nekrotik pulpalı dişlerin apekslerinde oluşan enflamatuar çene kistleridir. Tüm çene kistleri arasında en yaygın olarak görülen kist tipidir ve çene kemiğini etkileyen kistlerin \%52-68'ini oluşturmaktadır. ${ }^{5}$ Apikal kistler çenelerde dişlerin bulunduğu tüm bölgelerde oluşabilmektedirler ancak maksiller dişlerde mandibuler dişlere göre daha sık görülmektedirler. Radiküler kistler üst çenede daha çok anterior bölgede görülmekte iken, alt çenede daha çok premolar bölgede oluşmaktadırlar. Radiküler kistlerin apikal periodontal lezyonlardaki Malessez epitelyum hücre artıklarının proliferasyonundan köken aldıkları düşünülmektedir. ${ }^{6}$ Radiküler kistlerin tedavisinde öncelikle ilgili dişe kanal tedavisi uygulanmakta, eğer gerekli görülürse apikoektomi ve retrograd dolgu ile birlikte kistin cerrahi eksizyonu yapılmaktadır. $^{7-9}$ Radiküler kist ile ilişkili eksternal enflamatuar kök rezorpsiyonunun tedavisinde, kök kanal tedavisi ile enfektif ajanın uzaklaştırılması takiben, rezorpsiyonun kontrol edilmesi ve kök kanal siteminin retrograd olarak kapatılması için mineral trioksit agregat (MTA) gibi anti-klastik terapötik bir ajan kullanılması, rezorbe olmuş kök yüzeylerinde sert doku formasyonunun stimülasyonunu sağlanmaktadır.

$\mathrm{Bu}$ vaka raporunda lateral periodontal kist görünümlü bir radiküler kist ile ekternal kök rezorpsiyonunun tedavisi sunulmaktadır.

\section{OLGU SUNUMU}

Rutin radyografik muayene sirasinda maksiller sol 1. premolar dişinin kökünün lateralinde radyolusent bir lezyon saptanan 54 yaşında bayan hasta, lezyonun tedavisi için Periodontoloji kliniğine başvurdu. Alınan anamnezde maksiler ilgili dişe 10 yıl önce kanal tedavisi uygulandığ 1 öğrenildi. Klinik muayenede dişte palpasyonda ve perkusyonda herhangi bir ağrı saptanmadı. Cep derinlikleri fizyolojik sınırlar içersinde, dişeti sağlıklı görünümdeydi. Radyolojik muayenede lateral periodontal kist görüntüsüne benzer radyolusent lezyon izleniyordu (Resim 1).

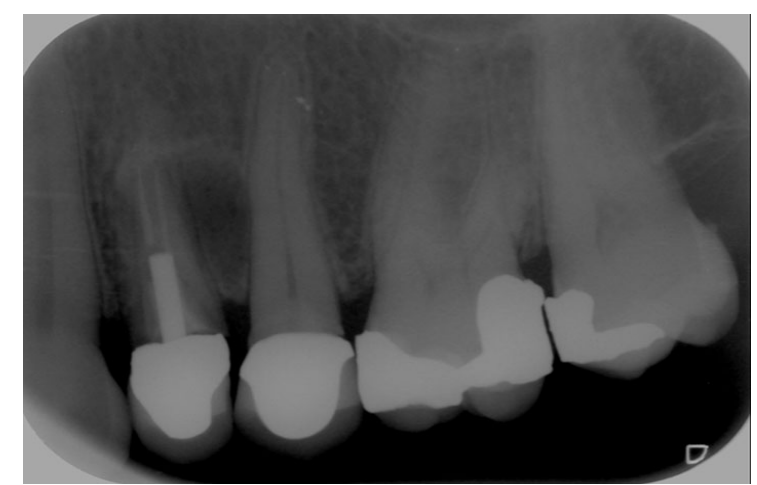

Resim 1. Hastanın tedavi öncesi periapikal ragyografisi.

Fakat 10 y1l önce yapılan kanal tedavisinden şüphelenilerek farklı açıyla bir periapikal film daha alındığında dişte eksternal kök rezorpisyonu ile ilişkili radiküler kist benzeri lezyon olduğu görüldü (Resim 2). Kanal tedavisinin yenilenmesine ve kistin cerrahi olarak çıkarılarak rezorbsiyon bölgesinin mineral trioksit agregat (MTA) ile kapatılmasına karar verildi. Hastaya uygulanacak tedavi prosedürü anlatılıp onamı alındıktan sonra tedaviye başlandı.

Maksiller sol 1. premolar dişin kanal tedavisi yenilendikten sonra, maksiller sol 1. ve 2. premolar dişleri içine alacak şekilde tam kalınlık mukoperiosteal flap kaldırıldı. 


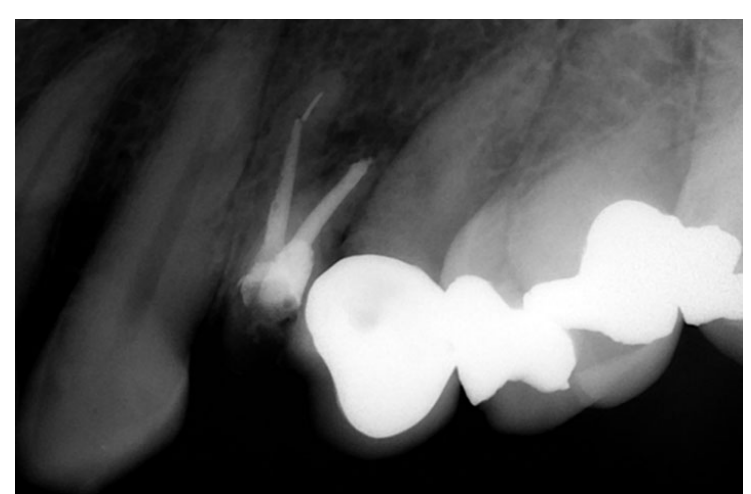

Resim 2. Hastanın tedavi öncesi açısı değiştirilerek alınmış periapikal radyografisi.

Dişin bukkal bölgesinden kiste ulaşım sağlandiktan sonra kist enükle edildi. Daha sonra Erbiyum, Krom: YittriyumScandiyum-Galyum-Garnet (Er,Cr:YSGG) lazer, ayarlar1 4 Watt, $20 \mathrm{~Hz}, \% 55$ su ve \%65 hava olacak şekilde yapıldıktan sonra dişin apikal rezeksiyonu gerçekleştirildi (Resim 3) ve apeksi MTA ile kapatıldı (Resim 4).

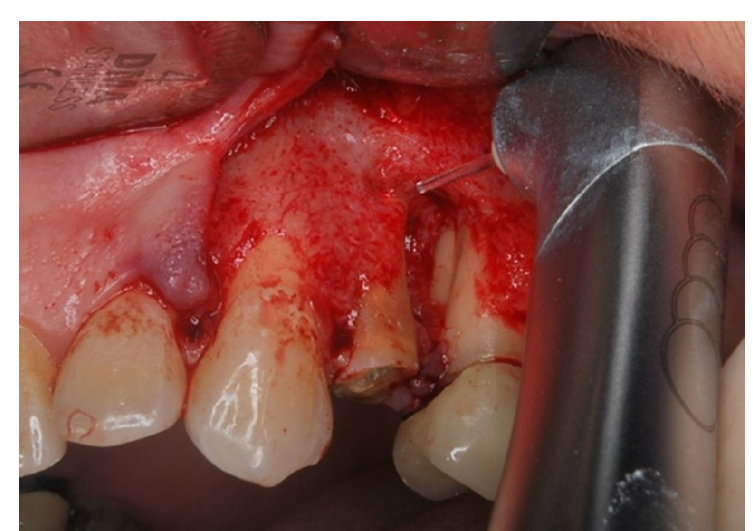

Resim 3. Kistin temizlendikten sonra dişin apeksinin Er,Cr:YSGG lazer ile rezeke edilmesinin görüntüsü.

Kistin temizlendikten sonra açığa çıkan kemik kavitesi Er,Cr:YSGG lazer ile 0,5 $\mathrm{W}, 20 \mathrm{~Hz}$ ve \% 20 su ayarları kullanılarak dezenfekte edildi. Daha sonra kemik kavitesi dekalsifiye, dondurulmuş, kurutulmuş kemik allogrefti (DDKKA) ile doldurularak (Resim 5) flap primer olarak kapatıldı.

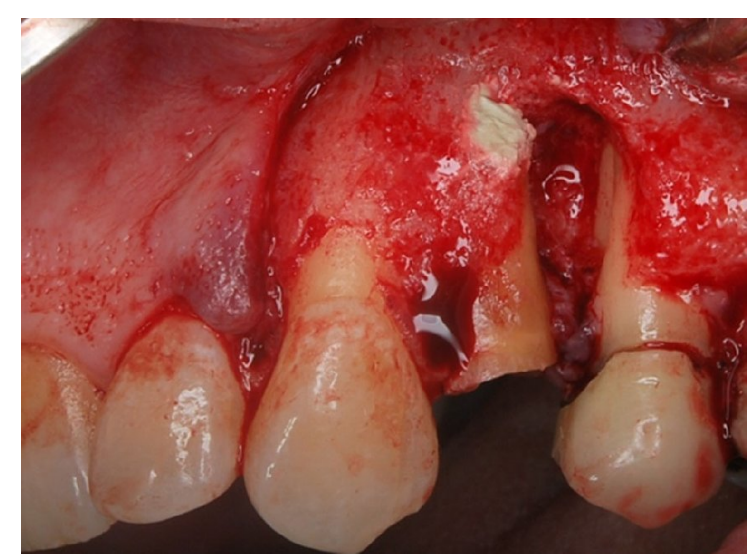

Resim 4. Dişin apeksinin MTA ile kapatılmış halinin görüntüsü.

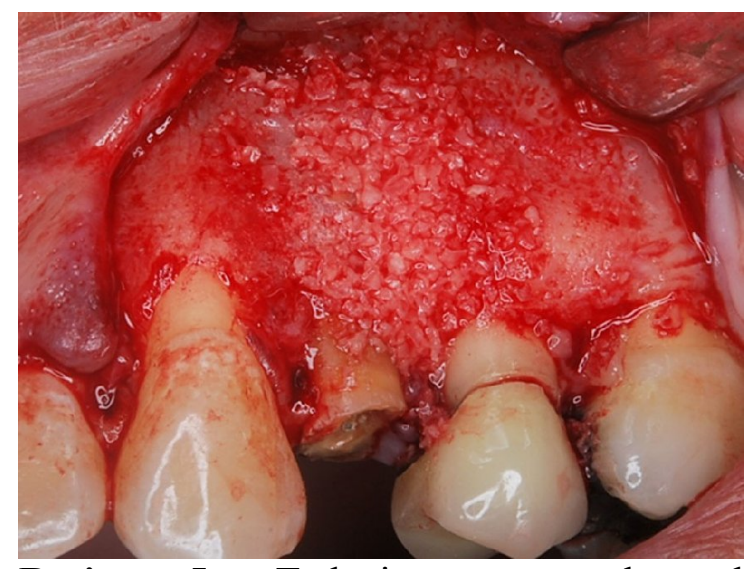

Resim 5. Tedavi sonrasi kontrol radyografisi.

Hastanın her ay düzenli klinik ve radyografik kontrolleri yapıldı. 3. ay sonunda klinik ve radyografik olarak bir patoloji izlenmediği için (Resim 6) hastanın protetik restorasyonu tamamland1 (Resim 7). 1. y1l sonucunda yapilan kontroller sonucu herhangi bir probleme rastlanılmadi (Resim 8).

\section{TARTISMA}

Pulpa nekrozunu takiben, kök kanal sisteminde bakterilerin kolonizasyonu ve proliferasyonu başlamaktadır. Bakteriler ve ürünlerinin yaptıkları kronik stimulus, periapikal bölgede enflamasyonun devam etmesine neden olmaktadır. ${ }^{10}$ Granülomlar ve periapikal kistler gibi proliferatif karakteri olan kronik periapikal lezyonlar bu sürecin sonucunda oluşmaktadırlar. $\mathrm{Bu}$ 


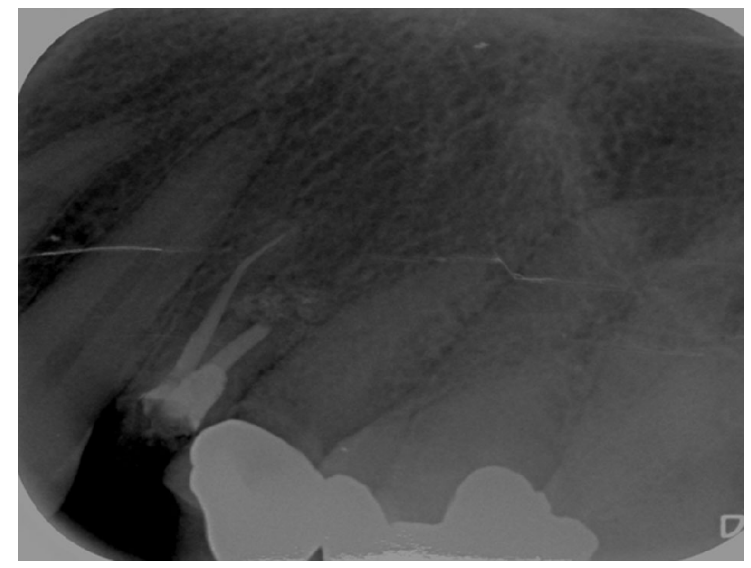

Resim 6. Kemik kavitesinin DDKKA ile doldurulduktan sonraki görüntüsü.

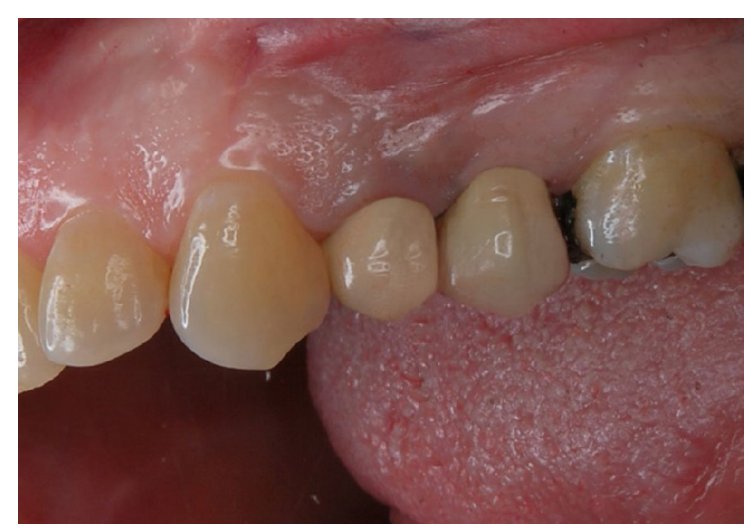

Resim 7. Kron restorasyonun bitirildikten sonraki görüntüsü.

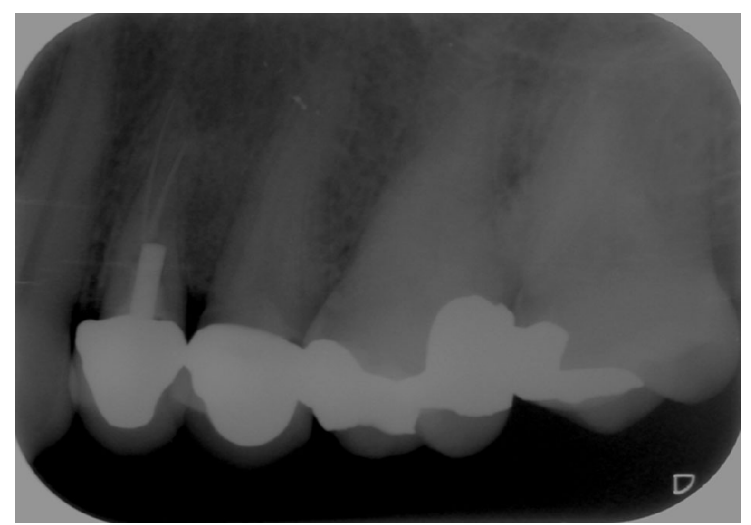

Resim 8. Dişin tedavi sonrası 1.y1l periapikal radyografisi.

lezyonların yavaş büyümeleri, kemik ve dişte radyografik olarak görülebilen rezorpsiyonlar ile sonuçlanmaktadır. ${ }^{10}$ İntraoral radyografiler birbirleri üzerine süperpoze olan görüntüler oluşturmaktadır ve bu görüntüler patolojinin mesiodistal genişliğini verirken, bukkolingual genişliğini verememektedir. $\mathrm{Bu}$ nedenle gözlemci iki boyutlu filme bakarak üç boyutlu bir karar vermek durumunda kalmaktadır. ${ }^{11,12}$ Periapikal lezyonları ve birbiri üzerine superpoze olan kökleri değerlendirirken, farklı açılardan birden fazla radyografi alınması faydalı olabilir. Paralel teknikle elde edilen radyografiler diğerlerine göre gerçeğe daha yakın boyutlarda görüntüye sahiptirler. Geleneksel olarak periapikal lezyonların teşhisi emprik yöntemler olan klinik ve radyografik bulgulara dayanmaktadır. Periapikal lezyonların ayırıcı tanısında cerrahi biyopsi ve histopatolojik değerlendirmeler altın standarttır. ${ }^{11,13,14}$ Radyolojik inceleme klinik teşhislerde önemli bir kaynaktır ancak yetersiz radyolojik incelemeye bağlı olarak konulan yanlış teşhis dişin çekimine, gerekli olmayan periodontal tedaviye ve lezyonun rekürrensine neden olabilmektedir. $\mathrm{Bu}$ vakada, başlangıçta alınan periapikal radyografiye nedeni ile lezyon LPK olarak düşünülerek tedavisi yapılsa ve önceki kanal tedavisi yenilenmeseydi, kistin rekürrensi ve tedavinin başarısız sonuçlanması kaçınılmaz olacaktı.

$\mathrm{Bu}$ vakada mevcut olan radiküler kist ve eksternal kök rezorpsiyonu önceden yapılmış olan başarısız kanal tedavisi ile ilişkili olduğundan ve lezyonun boyutu büyük olduğundan cerrahi endodontik tedavi (apisektomi) uygulanmıştır. Apisektomi Er,Cr:YSGG lazer ile yapılmış ve retrograd dolgu alarak MTA kullanılmıştır. Kök ucunun rezeksiyonunda döner aletler, ultrasonik cihazlar ve lazerler kullanılmaktadır. Bu cihazların sert doku üzerindeki etkinliğini değerlendiren farklı araştırmalar $^{9,15-21}$ bulunmaktadır. Yüksek hızlı döner aletlerle yapilan apikal rezeksiyonun daha hızlı bir yöntem olduğu rapor edilmiştir. Ancak frezlerin oluşturduğu düzenli olmayan kesim yüzeylerini saran smear tabakas1, mikroorganizmaların apikal bölgede kalmasına ve döner aletlere bağlı olarak 
ortaya çıkan termal değişiklik kollateral hasara ve perforasyon riskine neden olmaktadır. Ultrasonik el aletlerinin, döner aletlere göre daha kontrol edilebilir olmaları ve kök kanalının merkezine yerleştirilmelerinin daha kolay olması nedeniyle perforasyon riski daha düşüktür. Ayrıca kanal ve kök ucu kavitesi bu aletler kullanıldığında daha iyi temizlenebilmektedir. ${ }^{9,15}$ Buna karşın, ultrasonik aletler kullanıldığında çatlak ve kırık formasyonu oluşabildiği ve bunun sonucunda oluşabilecek apikal sızıntının tedavinin uzun dönem prognozunu etkileyebileceği bildirilmiştir. ${ }^{9,15,19}$

Erbiyum grubu lazerler apikal rezeksiyonda ve apikal örtücülüğün sağlanabilmesi için kök ucu preparasyonunda kullanılmaktadır. $\mathrm{Bu}$ grup lazerlerden biri olan Er,Cr:YSGG lazerin 1şığının dalga boyu $2780 \mathrm{~nm}$ ' dir ve suda ve $\mathrm{OH}^{-}$iyonlarında yüksek derecede absorbe olmaktadır. Bu lazer, eksternal su varlığında sert dokularda minimum is1 artışı ve karbonizasyon oluşturarak, fototermo-mekanik ablasyon mekanizmasiyla sert dokuları uzaklaştırmak için kullanılmaktadır. ${ }^{19,21,22}$ Lazer kullanıldığında tedavi prosedürü daha uzun sürse de, diğer yöntemlerle karşılaştırıldığında lazer ile yapilan tedavinin daha hassas olması $^{23}$, kırık veya çatlak oluşmaması, smear tabakasını uzaklaștırması, 15,19,21,24 komşu dokularda oluşan rahatsızlığın, vibrasyonun ve travmanın daha az olmasi ${ }^{20}$ gibi avantajları bulunmaktadır. Lazer kullanımının apikal dentinal geçirgenliği azalttığı da bulgulanmıştır. Smear tabakasının uzaklaştırılması, açığa çıkan dentinal tübüllerin içine retrograd dolgunun penetre olmasinı ve uzantılar yapmasını sağlamaktadır. Winik ve ark. ${ }^{8}$ Er,Cr:YSGG laser uygulaması sonrasinda kanal patlarının penetrasyonunu ve marjinal sızıntılarını değerlendirmişlerdir. Lazer uygulaması ile birlikte ve MTA kullanımının kanallarla daha iyi penetre olduğunu göstermişlerdir. Karlovic ve ark. $^{15}$ ise Er:YAG lazer ve ultrasonik cihazı kenar örtücülüğü açısından karşılaştırmışlar ve lazer grubunun belirgin derecede daha düşük mikrosızıntı gösterdiğini tespit etmişlerdir.

Retrograd dolgu materyalinin iyi adapte edilmesi periradiküler cerrahinin başarısında önemli bir rol oynamaktadır. Bu vakada, biyouyumlu olmas1, uygulanan alanın kuru olmasinı gerektirmemesi, uygulamasının kolay olmasi, $, 8,25,26$ daha düşük mikrosızıntı göstermesi, kavite duvarlarına adaptasyonunun iyi olması ve sert doku oluşumunu indüklemesi ${ }^{8,15}$ nedeniyle, retrograd dolgu materyali olarak MTA tercih edilmiştir. MTA' nın içeriğinde temel olarak trikalsiyum silikat, dikalsiyum silikat, trikalsiyum alüminat, trikalsiyum oksit ve kalsiyum fosfat bulunmaktadır. ${ }^{9,27} \mathrm{Su}$ ile karıştırıldığında, trikalsiyum silikat ve dikalsiyum silikat hidrate olarak, alkalin kalsiyum silikat jeli oluşturmaktadır. Alkalen olması MTA' ya biyouyumluluk ve antimikrobiyal özellik kazandırmaktadır. ${ }^{27}$ Kalsiyum oksit su veya doku sıvıları ile reaksiyona girerek kalsiyum hidroksiti oluşturmakta ve daha sonra kalsiyum ve hidroksil iyonlarına ayrışmaktadır. Kalsiyum iyonları ve karbon dioksit tarafindan oluşturulan kalsiyum karbonat granülleri kemik, dentin ve sement depozisyonunu stimüle etmektedir. ${ }^{9,25,26,28}$ Apisektomi ve retrograd dolgu prosedürlerinden sonra, kemik defekti rejenerasyon için DDKKA ile doldurulmuştur. Rejeneratif işlemler bariyer membranları ve/veya kemik greft materyalleri kullanılarak yapılmaktadır ve yönlendirilmiş kemik rejenerasyonunun amacı, çevre dokuların büyümesini teşvik ederek ve epitel hücreleri gibi istenmeyen hücrelerin oluşumunu engelleyerek yeni kemik oluşumu için bir matriks sağlamaktır. ${ }^{29}$

Sonuç olarak, radiküler kist ile birlikte seyreden eksternal kök rezorbsiyonu vakalarında, başarılı bir kanal tedavisi ile birlikte rezorpsiyon bölgesinin rezeksiyonunu takiben MTA ile apikal tıkanmanın sağlanması ve kistin enükleasyonu sonucu oluşan kemik 
kavitesinin DDKKA ile doldurulması, uygun bir tedavi yaklaşımı olabilir.

\section{KAYNAKLAR}

1. Nart J, Gagari E, Kahn MA, Griffin TJ. Use of guided tissue regeneration in the treatment of a lateral periodontal cyst with a 7-month reentry. J Periodontol 2007;78:1360-1364. [CrossRef]

2. Méndez $P$, Junquera L, Gallego L, Baladrón J. Botryoid odontogenic cyst: clinical and pathological analysis in relation to recurrence. Med Oral Patol Oral Cir Bucal 2007;12:E594598.

3. Hethcox JM, Mackey SA, Fowler CB, Kirkpatrick TC, Deas DE. Case report: Diagnosis and treatment of a botryoid odontogenic cyst found in the maxillary anterior region. $\mathrm{J}$ Endod 2010;36:751-754. [CrossRef]

4. Bataineh $\mathrm{AB}$, Rawashdeh $\mathrm{MA}, \mathrm{Al}$ Qudah MA. The prevalence of inflammatory and developmental odontogenic cysts in a Jordanian population: a clinicopathologic study. Quintessence Int 2004;35:815-819.

5. Nair PN. New perspectives on radicular cysts: do they heal? Int Endod J 1998;31:155-160. [CrossRef]

6. Lin LM, Ricucci D, Lin J, Rosenberg PA. Nonsurgical root canal therapy of large cyst-like inflammatory periapical lesions and inflammatory apical cysts. J Endod 2009;35:607-615. [CrossRef]

7. Ricucci D, Siqueira JF Jr. Anatomic and microbiologic challenges to achieving success with endodontic treatment: a case report. J Endod 2008;34:1249-1254. [CrossRef]

8. Winik R, Araki AT, Negrão JA, BelloSilva MS, Lage-Marques JL. Sealer penetration and marginal permeability after apicoectomy varying retrocavity preparation and retrofilling material. Braz Dent J 2006;17:323-327. [CrossRef]

9. Kim S, Kratchman S. Modern endodontic surgery concepts and practice: a review. J Endod 2006;32:601-623. [CrossRef]

10. Vier FV, Figueiredo JA. Prevalence of different periapical lesions associated with human teeth and their correlation with the presence and extension of apical external root resorption. Int Endod J 2002;35:710-719. [CrossRef]

11. Aggarwal V, Logani $A$, Shah N. The evaluation of computed tomography scans and ultrasounds in the differential diagnosis of periapical lesions. J Endod 2008;34:1312-1315. [CrossRef]

12. Cotton TP, Geisler TM, Holden DT, Schwartz SA, Schindler WG. Endodontic applications of cone-beam volumetric tomography. $\mathrm{J}$ Endod 2007;33:1121-1132. [CrossRef]

13. Simon JH, Enciso R, Malfaz JM, Roges R, Bailey-Perry M, Patel A. Differential diagnosis of large periapical lesions using cone-beam computed tomography measurements and biopsy. J Endod 2006;32:833-837. [CrossRef]

14. Rosenberg PA, Frisbie J, Lee J, et al. Evaluation of pathologists (histopathology) and radiologists (cone beam computed tomography) differentiating radicular cysts from granulomas. J Endod 2010;36:423428. [CrossRef]

15. Karlovic Z, Pezelj-Ribaric S, Miletic I, Jukic S, Grgurevic J, Anic I. Erbium:YAG laser versus ultrasonic in preparation of root-end cavities. $\mathrm{J}$ Endod 2005;31:821-823. [CrossRef]

16. Grgurević J, Grgurević L, Miletić I, Karlović Z, Krmek SJ, Anić I. In vitro study of the variable square pulse Er:YAG laser cutting efficacy for apicectomy. Lasers Surg Med 2005;36:347-350. [CrossRef]

17. Oliveira RG, Gouw-Soares $S$, Baldochi SL, Eduardo CP. Scanning electron microscopy (SEM) and optical microscopy: effects of Er:YAG and Nd:YAG lasers on apical seals after apicoectomy and retrofill. 
Photomed Laser Surg 2004;22:533536. [CrossRef]

18. Francischone CE, Padovan LA, Padovan LE, Duarte MA, Fraga Sde C, Curvêllo VP. Apicectomy with the Er:YAG laser or bur, followed by retrograde root filling with zinc oxide/eugenol or sealer 26. Photomed Laser Surg 2005;23:395-398. [CrossRef]

19. Rahimi S, Yavari HR, Shahi S, Zand V, Shakoui S, Reyhani MF, Pirzadeh A. Comparison of the effect of $\mathrm{Er}, \mathrm{Cr}$ YSGG laser and ultrasonic retrograde root-end cavity preparation on the integrity of root apices. J Oral Sci 2010;52:77-81. [CrossRef]

20. Duarte MA, Domingues R, Matsumoto MA, Padovan LE, Kuga MC. Evaluation of apical surface roughness after root resection: a scanning electron microscopic study. Oral Surg Oral Med Oral Pathol Oral Radiol Endod 2007;104:e74-76. [CrossRef]

21. Batista de Faria-Junior N, TanomaruFilho M, Guerreiro-Tanomaru JM, de Toledo Leonardo R, Camargo Villela Berbert FL. Evaluation of ultrasonic and ErCr:YSGG laser retrograde cavity preparation. $\mathrm{J}$ Endod 2009;35:741-744. [CrossRef]

22. Cobb CM. Lasers in periodontics: a review of the literature. J Periodontol 2006;77:545-564. [CrossRef]
23. Reyhanian A, Parker S, Moshonov J. The use of the erbium yttrium aluminium garnet $(2,940 \mathrm{~nm})$ in a laser-assisted apicectomy procedure. Br Dent J 2008;205:319-323. [CrossRef]

24. Wallace JA. Effect of Waterlase laser retrograde root-end cavity preparation on the integrity of root apices of extracted teeth as demonstrated by light microscopy. Aust Endod J 2006;32:35-39. [CrossRef]

25. Yilmaz HG, Kalender A, Cengiz E. Use of mineral trioxide aggregate in the treatment of invasive cervical resorption: a case report. J Endod 2010;36:160-163. [CrossRef]

26. Gomes-Filho JE, Watanabe S, Bernabé PF, de Moraes Costa MT. A mineral trioxide aggregate sealer stimulated mineralization. $\mathrm{J}$ Endod 2009;35:256-260. [CrossRef]

27. Zhang H, Pappen FG, Haapasalo M. Dentin enhances the antibacterial effect of mineral trioxide aggregate and bioaggregate. $\mathrm{J}$ Endod 2009;35:221-224. [CrossRef]

28. Yildirim $T$, Gençoğlu N. Use of mineral trioxide aggregate in the treatment of horizontal root fractures with a 5-year follow-up: report of a case. J Endod 2009;35:292-295. [CrossRef]

29. Bashutski JD, Wang HL. Periodontal and endodontic regeneration. J Endod 2009;35:321-328. [CrossRef] 